\title{
The Chalcolithization Process: Dynamics of Shiqmim Site-cluster (Northern Negev, Israel)
}

\author{
Augustin Ferdinand Charles Holl \\ Department of Anthropology and Ethnology, Africa Research Center, Xiamen University, Xiamen, P. R. China \\ Email address: \\ gaochang@xmu.edu.cn \\ To cite this article: \\ Augustin Ferdinand Charles Holl. The Chalcolithization Process: Dynamics of Shiqmim Site-cluster (Northern Negev, Israel). International \\ Journal of Archaeology. Vol. 7, No. 2, 2019, pp. 30-46. doi: 10.11648/j.ija.20190702.12
}

Received: June 19, 2019; Accepted: July 27, 2019; Published: September 24, 2019

\begin{abstract}
The Northern Negev Chalcolithic Period is supposed to have lasted for approximately 1000 years, from $c a$. 4500 to $3500 \mathrm{BCE}$. Its beginning and end, as well as internal evolution are hotly debated topics. Archaeological evidence features the accelerated diversification of Late Neolithic mixed-farming societies and expansion into new territories. Some of these groups, through a "chalcolithization" process, adopted copper metallurgy, polychrome pottery and V-shape bowls. There is a punctuated shift with an initial differential adoption of new cultural practices that rippled afterward across the whole Levant through population admixtures. The internal dynamics of the Southern Levantine Chalcolithic societies is generally addressed through an inadequate time-frame and field methodology, ie stretched inferences derived from a single-site in an undifferentiated Chalcolithic time block. The Shiqmim hamlets project carried out in 1993, -with its own limitations-, allows to discuss the formation and evolution of a tight chalcolithic site-cluster. As featured in this paper, the analysis of the internal dynamics of chalcolithic societies requires a regional framework, a fine-grained rendering of sites occupation histories, and a high-resolution chronology.
\end{abstract}

Keywords: Chalcolithization, Site-cluster, Settlement Patterns, Evolutionary Modelling, Population Admixture, Shiqmim, Northern Negev, Israel

\section{Introduction}

This study intends to explore the genesis and evolution of a Chalcolithic settlement cluster in northern Negev. The term Chalcolithic is used to refer to a time segment stretched between the Late Neolithic mixed-farming communities and the Early Bronze Age urban societies in the western half of Eurasia. It is singled out by the relative routinization of the production and use of copper objects and polychrome usually white and red - ceramics. As can be expected in this kind of "time-cultural" taxonomy, the beginning, chronological evolution, internal diversity, as well as the end of the Chalcolithic period, are hotly debated by experts [112]. There are many different Chalcolithic communities relying differentially on agriculture and livestock husbandry. Mediterranean arboriculture - with the cultivation of olives, grapes, and very likely oranges - for example, with its strong social implications, has its roots in the circum-Mediterranean Chalcolithic.

\section{Chalcolithization as Process}

If asked how did Chalcolithic societies emerge and devolve, most scholars involved in the debate will answer: "through a transition from the Late Neolithic to the Chalcolithic for its emergence, and from the Chalcolithic to the Early Bronze Age for its devolution”. The concept of "transition" is accordingly used to refer to the beginning and the end of the Chalcolithic period. In Southern Levant for example [1, 13, 14, 6, 11, 15], Chalcolithic origins are framed as an initial phase-transition from the Late Neolithic and its end as another ultimate phase-transition to the Early Bronze Age. In that gradualist conception, space and time drift generates new cultural packages leading to the coalescence of a novel socio-cultural entity, in this case, the Southern Levantine Chalcolithic Period, that lasted for some 800 - 1000 years, from $c a .4500$ to 3500 BCE.

Gilead's [5] argument on the origins of northern Negev Chalcolithic societies is articulated on three propositions: 
1) The persistent fragmentary nature the Levantine Late Neolithic record;

2) A shift of settlement to the southern semi-arid zones; and,

3) the absence of stratigraphic continuity between the Late Neolithic and the Chalcolithic.

The northern Negev Chalcolithic is accordingly inferred to have been intrusive, via the Qatifian (culture or period or both?) documented in the Sinai and northern Negev [6].

More recent research has widened the options and injected more diversity in the Late Neolithic - Chalcolithic evolutionary scenarios $[11,12]$. Bourke [15] has shown that the Ghassulian - or Tulaylat al-Ghassul Chalcolithic - was a direct development from the earlier Late Neolithic. Identical situations are documented at Abu Hamid and Wadi Ziqlab 200 in the Jordan valley [12]. Rowan and Golden's [12] synthetic review of the Chalcolithic period in the southern Levant deals with issues of initial and final transitions, regional diversity, and mortuary traditions. Their take on the initial transition from Late Neolithic to Chalcolithic is rather conflicted. The transition seems to have operated within an accelerated pace of regional diversification with a relatively large number of recorded "archaeological taxa": "Wadi Rabah, Qatifian, Besorian, Jericho VIII-IX, coastal Neolithic, Lodian, Yarmukian ..." [12]. It is thus asserted that all this diversification resulted in the formation of a "normative Chalcolithic" via Wadi Rabah. It is difficult to understand how one of the taxa - Wadi Rabah - among many resulting from the Late Neolithic diversification process re-integrates all the others and paved the way to a "normative Chalcolithic". In fact, what is a 'normative Chalcolithic'?

It is well known that change is constant and stability the exception. The accelerated trend toward Late Neolithic cultural diversification was partly fueled by noticeable environmental change and landscape diversity. Such diversification generally takes place among scattered communities settled along a moving frontier and entering diverse environmental settings. If viewed in socio-dynamic perspectives, such evolutionary processes were not transitional. What can be the meaning of a socio-cultural transition that lasts for 200-500 years? There are profound differences between the "archaeological cultural" taxonomies, devised to organize the constitutive similarities and differences in the observed material culture, and the dynamic processes that generated and sustained long-term social change.

Rowan and Golden [12] wrestled with that issue and were unfortunately constrained to an unsatisfactory exit. "For the present discussion, other traditions such as Jericho VIII, Pottery Neolithic B and coastal Neolithic are treated as one basic archaeological entity that fits within the definition of Wadi Rabah and its regional variations" [11]. The documented diversity is subsumed under one of the recorded taxa: "Wadi Rabah as a larger archaeological culture with regional subcultures establishing a pattern that continues into the Chalcolithic" [12].

The 'archaeological culture' taxonomy is problematic. The named complex - culture - takes a virtual independent life of its own and constrains researchers thinking. "The name is not the thing" [16]. Genomic evidence [7, 8, 10] points to extensive population admixture when Late Neolithic mixedfarming communities spread in different Middle Eastern environmental settings, started to adopt the production and used of copper artifacts in the fifth millennium BCE, in differential and punctuated shifts to new cultural practices [15]. Identifying and tracing the dynamic evolutionary processes that drove and sustained complex adaptive systems are crucial in anthropological archaeological research. It is a sample of such dynamic and evolutionary processes that is addressed in this paper.

\section{Methodology}

The southern Levantine Chalcolithic Period library is rich and impressive. Large site excavations are generally the norm in this part of the world. Attempts at anthropological interpretation of the archaeological record are severely hampered by the local standard field methodologies. Rowan and Golden's [12] diagnostic is pointedly accurate: "The priority in current Chalcolithic research, though is to answer questions about chronology, for without a more precise timeframe with which to work, it is impossible to study change in any area of the Chalcolithic society." The colonization processes and site location strategies that resulted in the formation of the northern Negev Chalcolithic cultural landscape are still poorly investigated.

Research permits are awarded on a single-site basis. Large sites are habitually selected for long-term excavation projects. Smaller sites and find-spots are sometimes mapped but are generally neglected. The northern Negev Chalcolithic settlement pattern consists of distinct sets of large village sites co-existing with smaller villages, hamlets and findspots, located along water courses [18-24]. There are ongoing debates about the sociopolitical nature of northern Negev Chalcolithic societies. The 353 sites recorded along the northern Negev water courses present obvious clustering [23, 24, 25]. A look at the map (Figure 1) shows distinct settlement aggregates distributed along the hydrographic networks. Six of these aggregates are relatively dense: Grar set on the Nahal Grar in the north; Safadi, Shiqmim, and Ze'elim sets along the Nahal Beersheva in the southeast; the Nahal Besor set in the southwest. Loose linear aggregates are found in the center around Gilat along the Nahal Patish and East of Beersheva city (Figure 1).

The recorded pattern is meaningful within the 1000-yearlong Chalcolithic time segment. Such loose chronological resolution, however, does not allow for the investigation of settlement nucleation, intra-site patterning, inter-site relationships, or regional settlement dynamics. All interested scholars would certainly agree with Rowan and Golden [12]: "The priority in current Chalcolithic research.... is to answer questions about chronology". In other words, high resolution chronology allowing for the investigation of contemporaneous cultural phenomena is absolutely essential 
for the understanding and explanation of past Chalcolithic social dynamics. Chalcolithic settlement clustering and dispersal, village layout concentration and/or nucleation, as well as fine-grained site locations strategies cannot be addressed within the paradigmatic single-site approach predominant in southern Levantine archaeology. New field strategies anchored on "regions", attentive to patterns of site formation and the elementary social units constitutive of the sites under investigation, are mandatory for a better understanding of Chalcolithic social dynamics.

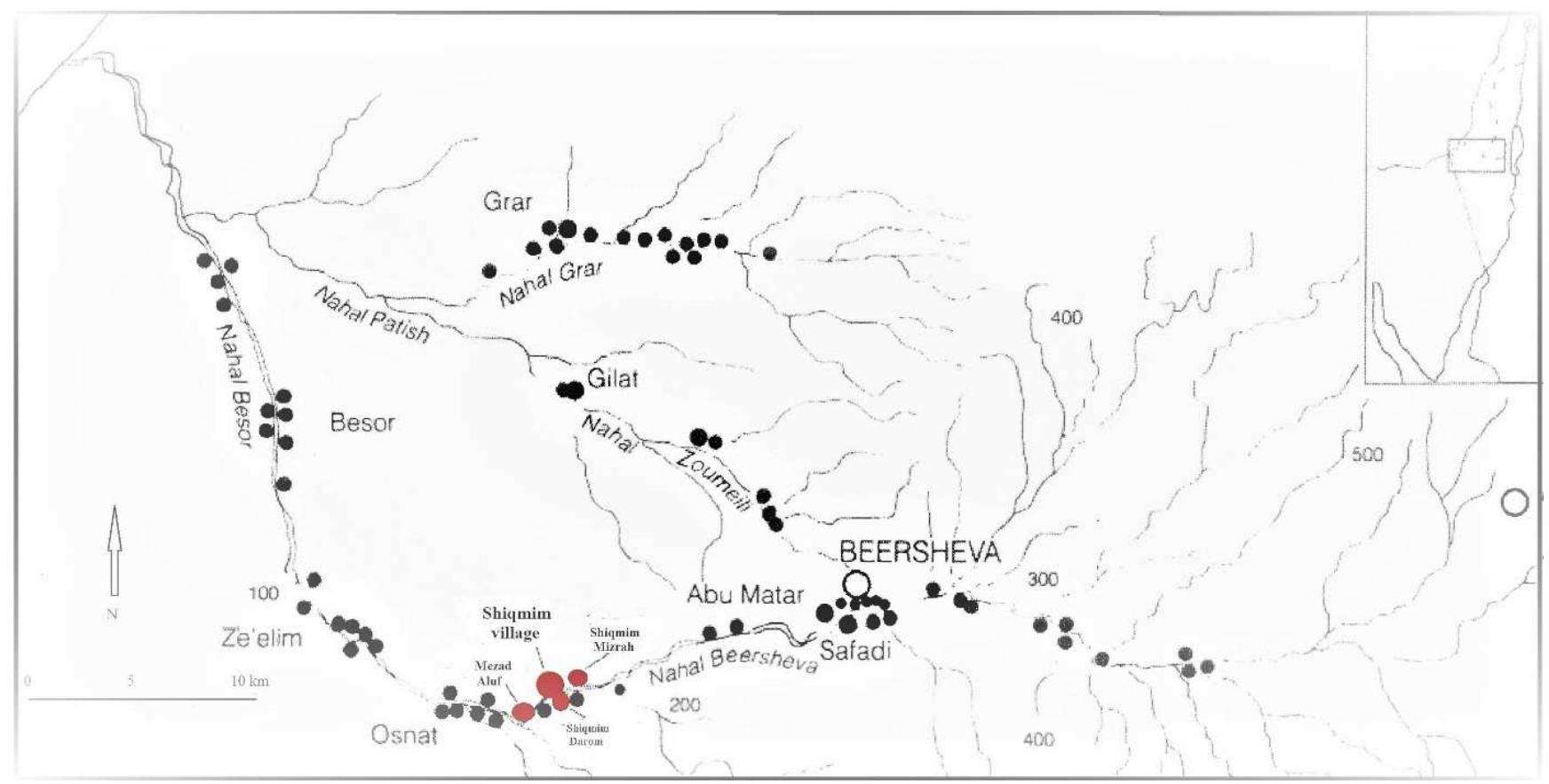

Figure 1. Shiqmim settlement cluster in the Northern Negev (modified after Levy et al 1991).

A regional framework is the optimal research strategy to address the dynamics of settlement systems. It was particularly successful in the writer's various field programs, in the the Dhar-Tichitt-Walata in Mauritania, Houlouf region in northern Cameroon, the Mouhoun Bend in Burkina Faso, and the Petit-Bao Bolon in Senegal [26-30]. All regional archaeology projects require explicit sampling strategies to choose the optimal options in terms of sites selection and excavation size. Smaller regional settings, as was the case with the $500 \mathrm{~km}^{2}$ study area delineated in the Houlouf region, allowed for the testing of all the recorded 15 mounds sites after 11 successive field seasons [27]. Cohorts of radiocarbon dates obtained from each tested site provided a relatively fine-grained chronology allowing to track shifts in regional settlement patterns.

The colonization of a semi-desertic land, even in circumstances of higher rainfall, is severely constrained by water availability. Mixed-farming communities tend to favor similar micro-environments with optimal crops production potentials. Pioneer settlements can accordingly be scattered all over the hydrographic networks of the colonized territories and their evolution can be modelled in two contrasted paths. In one, the centripetal model, initial settlements may have started at one locality, population growth leading to the foundation of successive generations of "daughter-communities", resulting in a cluster of linked settlements. In the other path, the centrifugal model at the opposite end of the spectrum, the initial settlements may consist of scattered small sites. One settlement, through its attractivity, may succeed in taking the lead, which triggers progressive abandonment of other smaller sites, with the population concentrating in a single large site. The best case for this scenario is Monte Alban in Mesoamerica [31]. The archaeological signatures of both settlement processes are identical. Ideally, only fine-grained chronologies obtained from the test of all or a few carefully selected and sampled sites can illuminate the process actually in operation. In fact, there are varying degrees of combinations of both kinds of settlement processes.

A systematic awareness of site formation processes allows one to assess the relative taphonomic integrity of archaeological features and contexts under investigation [32, 33]. The formation of the archaeological record results from the unstable balance between $\mathrm{C}$-transforms and $\mathrm{N}$ transforms. C-transforms [Cultural-transforms] include the material by-products of all human life-sustaining activities. $\mathrm{N}$-transforms [Natural-transforms] comprise the impacts of all natural phenomena that either enhance the preservation of or disturb the archaeological record. It has already been shown that the sedimentary depositional units of the Northern Negev Chalcolithic sites resulted from house construction, use activities, abandonment and decay [34].

An assessment based on potsherds distribution, quantity, weight, density per $\mathrm{m}^{2}$, and fragmentation indexes has shown that topsoil and fills contain the largest amount of sherds and living floors the lowest. Fills are made of collapsed walls containing large quantity of sherds that was included in the mudbricks matrix of walls and house superstructures [32, 
34]. The sherds populations from these depositional units resulting from unintentional recycling are accordingly in secondary contexts with low taphonomic integrity. In contrast, sherds from living floors, larger on the average with low fragmentation indexes, originate from primary contexts with high taphonomic integrity. These distinct sherds populations with different taphonomic trajectories have to be analyzed separately and not lumped together as is frequently the case.

Four depositional units are accordingly recorded as part of each building phase deposit [or stratum] at Shiqmim-Village site: surface, topsoil, fills, and living floors. Their material culture contents are derived from different formation processes. Without careful consideration of site formation processes, behavioral interpretation can be misleading. Porath [35] had great difficulty interpreting the fills in a well preserved Chalcolithic house at Fasa'el in the lower Jordan valley. To make sense of the recorded evidence, he suggested that "the occupants of the structure never seem to have bothered to clear out any of their refuse and left it to accumulate on the floor, causing a gradual rise of the living level over the whole period of occupation of the site" [35].

Addressing the evolutionary trajectories of Chalcolithic societies requires a clear and sustained identification of the elementary social units visible in the archaeological record. Households are such units, generally delineated by habitation units $[34,36,37]$. They represent an economic and social cooperation unit that does not necessarily imply strict coresidence, even if that variable is the most recurrent one [37]
The household structure is articulated above all on kinship relations. It ensures five prominent functions: the social and biological reproduction, production sensu lato, transformation, distribution/consumption, and transmission of wealth and social attributes. Despite caution voiced by cultural anthropologists, co-residence is the determining factor in archaeological contexts:

... a doubt has been frequently raised as to the status of "residence" as a criterion for the analysis of the family, whether comparisons are being made over space or through time. There are nonetheless perfectly sound reasons for considering that the number of persons who sleep and frequently, if not invariably, take meals together under the same roof constitute a unit for social analysis, and can form a basis for revealing intersociety comparisons, particularly if due attention is given to the means by which that unit has been brought together [36].

The investigation of Chalcolithic settlement clustering has to address nested research problems revolving around regional archaeology, site formation processes, and the identification of the elementary social units represented in the investigated archaeological sites. The writer introduced these approaches in the "Chalcolithic Settlement of the Northern Negev Project" directed by T. E. Levy and David Alon from 1984 to 1996 [39-42]. He directed the excavation of two habitation units at Shiqmim-village and conducted the Shiqmim Hamlets project with a small group of bright international students.

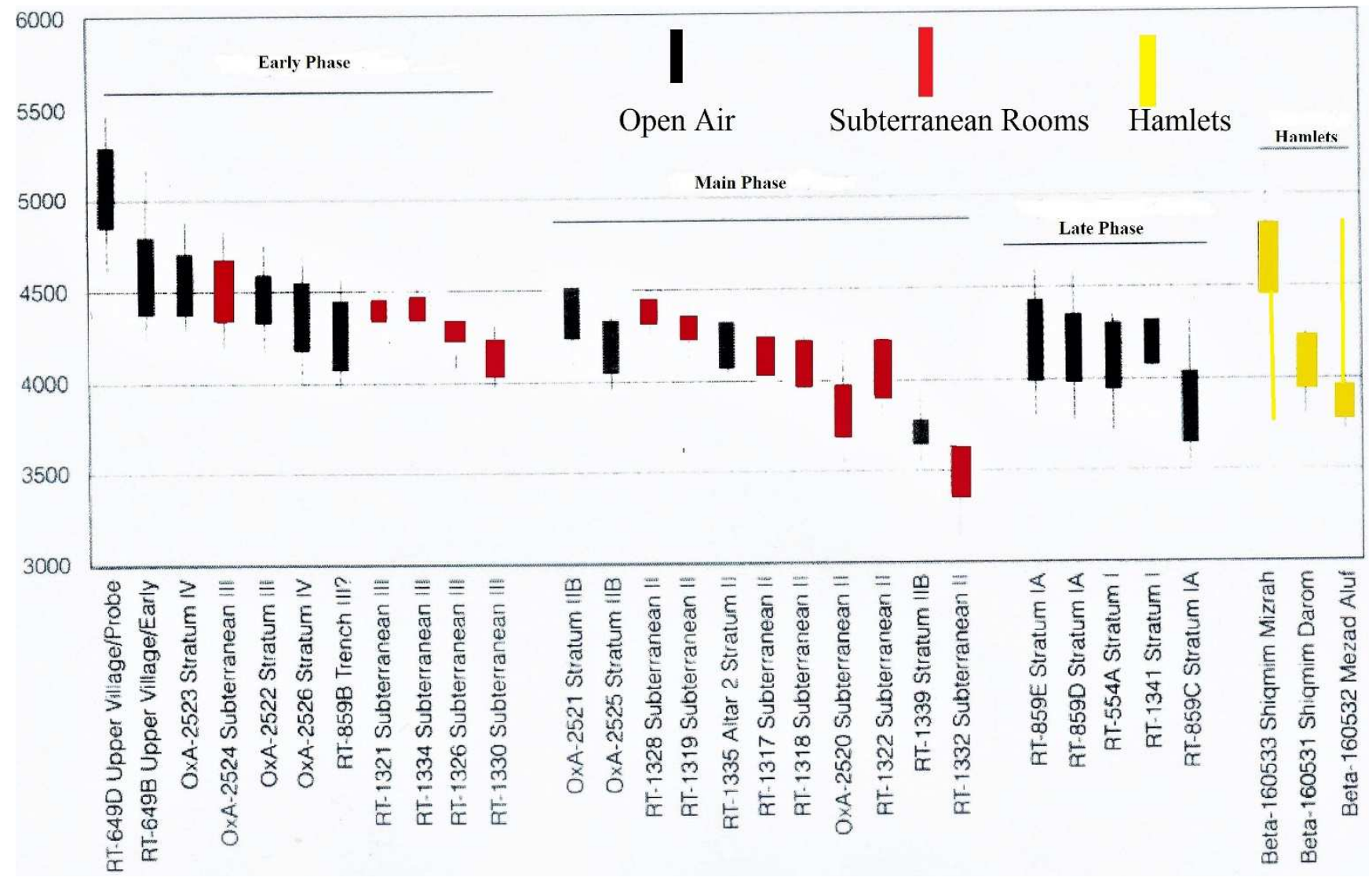

Figure 2. Shiqmim settlement cluster chronology (adapted from Levy et al 2006: 55). 


\section{The Shiqmim Settlement Cluster}

The Shiqmim settlement cluster, part of the Northern Negev Chalcolithic occupation, is located along the Nahal Beersheva. The territory of this Chalcolithic polity is delimited by the Nahal Sekker in the east and the Nahal Hippuchit in the west (Figure 1). It is comprised of 6 archaeological sites distributed over a $5 \mathrm{kms}$ long land stretch on both river banks. Shiqmim-village, spread over 9.5 ha on the north bank, is the largest settlement of the cluster. 4500 $\mathrm{m}^{2}$ of the site were excavated. The recorded archaeological deposit is $5 \mathrm{~m}$ thick, for an occupation that lasted for more than 1000 years (Figure 2) [41]. The Shiqmim Hamlets project designed and carried out by the writer in 1993 sampled 3 settlements of varying size located in Shiqmim countryside [43]. The tested sites were selected according to their location relative to the main settlement. Mezad Aluf, a 5.54 ha village, is located at $1.2 \mathrm{~km}$ west of Shiqmim. Shiqmim-Darom, just across the river bed on the south bank at less than $0.5 \mathrm{~km}$ from the main site, is a small 1.75 ha hamlet. And finally, Shiqmim Mizrah, a 1.20 ha hamlet, is located approximately $1 \mathrm{~km}$ east of Shiqmim-village. Not surprisingly and as shown by the available radiocarbon dates and material culture analyses, all the tested sites belong to the Chalcolithic period. Unfortunately, each of the tested sites beside Shiqmim-village is poorly dated with a single radiocarbon date for each locality (Figure 2), hampering any attempt at understanding the dynamics of Chalcolithic settlement clustering. Such an attempt is carried out in the remaining portion of this paper, through detailed intra- and inter-site analyses of the available architectural evidence. The material for this discussion is gathered from published data, personal field notes, drafted maps, and photographs from fieldwork conducted from 1984 to 1996 within the "Chalcolithic Settlements of the Northern Negev Project" directed by Thomas E. Levy and David Alon.

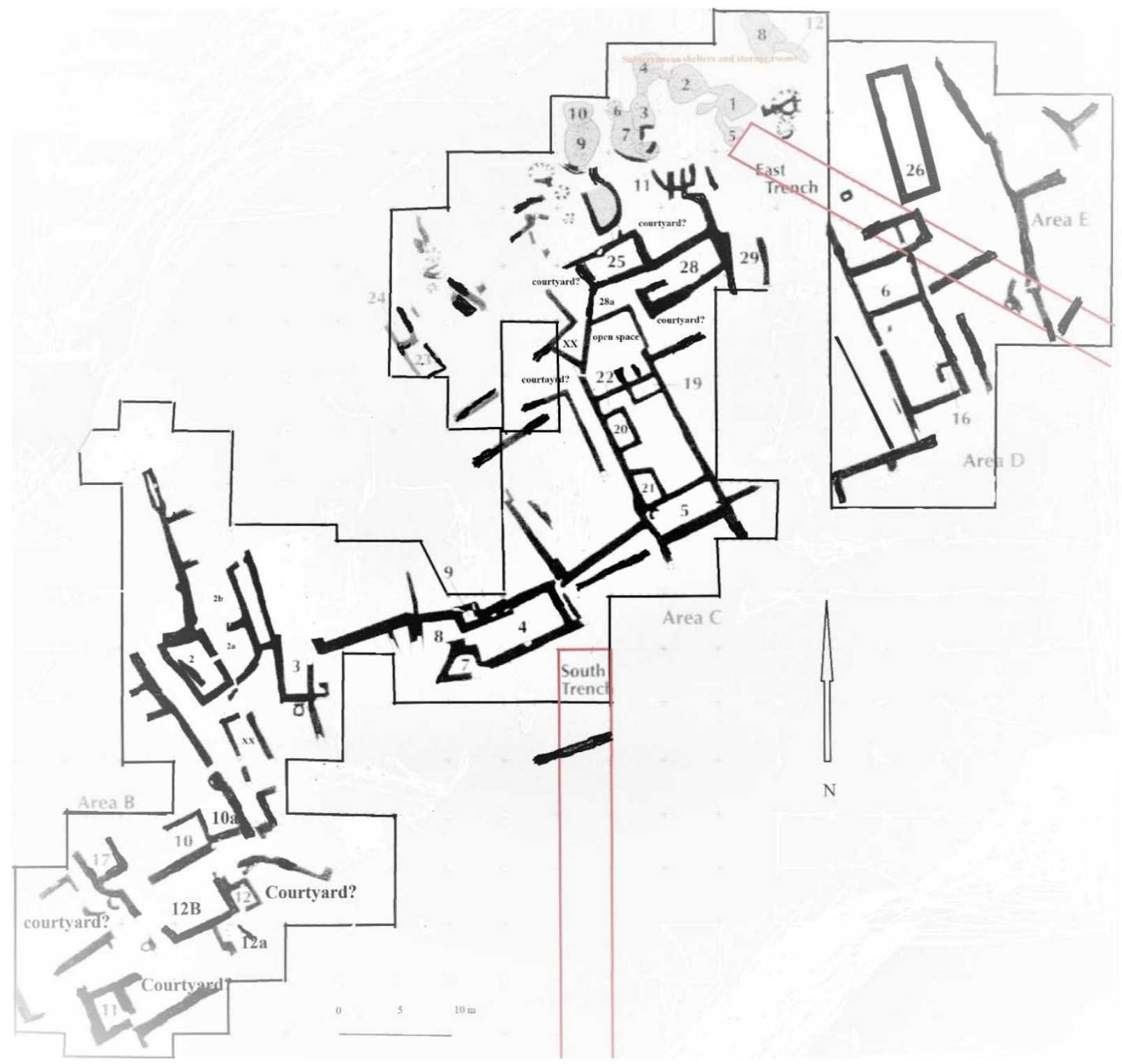

Figure 3. Shiqmim-village Main Phase (adapted from Levy et al 1991: 400). 


\subsection{Shiqmim-Village: An Intra-site Analysis}

$4500 \mathrm{~m}^{2}$, almost half of the Shiqmim-village surface, were excavated, making it the largest exposure of a Chalcolithic site in the northern Negev. The earliest occupation documented at the bottom of a $5 \mathrm{~m}$ thick archaeological deposit was reached through two deep trenches and one deep probe. "Test excavations in the lower village have shown clear evidence of at least 4 possibly 5 main architectural building phases." [43]. The intra-site analysis to be carried out accordingly focus on the best exposed segments of the site occupation history. Shiqmim-village occupation sequence is thus divided into a Main and a Late Phase. The Main Phase combines rectilinear stone and mudbrick houses and subterranean features, the latter used for storage and protection in cases of threat (Figure 3).

(i). The Main Phase

The Main Phase includes 13 habitation units (HU) and a large, probably public, building 26 (table 1, Figure 3 ). 3 are located in Area A, 4 in Area B, 5 in Area C, and 1 in Area D.
Three of the recorded HU located in Area A and B are made of single rooms. HU 3 and $\mathrm{HU}$ XX in Area A are rectangular $23.80-24.50 \mathrm{~m}^{2}$ rooms, $3.50 \mathrm{~m}$ wide and $6.80-7.00 \mathrm{~m}$ long. HU 17, from Area B, probably represents the southern portion of a larger building (Figure 3). In fact, single room HU appears to be an artifact of the excavation sampling. A habitation complex with a courtyard appears to have been the norm during the Main Phase.

The reconstruction of the HU structures is problematic in Area A and B. HU 2 may have included a $6 \times 5$ m courtyard $2 \mathrm{~b}$, and room 2 and $2 \mathrm{a}$, totaling $86 \mathrm{~m}^{2}$. A similar situation occurs in Area B in HU 10, 11, and 12 (Figure 3). Room 10 may have been part of a HU located along the west flank of an alley with space 10a as courtyard. The same applies to HU 11, with room 11 that could have been attached to the courtyard on its east flank, and HU 12, with a relatively large courtyard and small rooms 12 and 12a. The situation of 12B is very ambiguous and undecidable. It could be a single room HU set along a west - east alley.

Table 1. Shiqmim Village Main Phase Housing.

\begin{tabular}{|c|c|c|c|c|c|}
\hline Habitation Unit & & Length (m) & Width (m) & Surface $\left(\mathrm{m}^{2}\right)$ & Aggregate $\left(\mathrm{m}^{2}\right)$ \\
\hline \multicolumn{6}{|l|}{ Area A } \\
\hline \multirow{3}{*}{ HU 2} & Courtyard? & 6.00 & 5.00 & 30.00 & \\
\hline & Room 2 & 8.00 & 4.00 & 32.00 & \\
\hline & Room 2a & 6.00 & 4.00 & 24.00 & 86.00 \\
\hline HU 3 & & 6.80 & 3.50 & 23.80 & 23.80 \\
\hline \multicolumn{2}{|l|}{ HU XX } & 7.00 & 3.50 & 24.50 & 24.50 \\
\hline Area B & & & & & \\
\hline \multirow{2}{*}{ HU 10} & Room 10 & 7.00 & 4.20 & 29.40 & \\
\hline & Room 10a & $?$ & $?$ & $?$ & $29.40 ?$ \\
\hline \multirow{3}{*}{ HU 11} & Room 11 & & 4.50 & 4.00 & 18.00 \\
\hline & Room 11a & ? & $?$ & $?$ & $18.00 ?$ \\
\hline & Room 12 & 2.80 & 2.40 & 6.72 & \\
\hline \multirow[t]{2}{*}{ HU 12} & Room 12a & $?$ & $?$ & $?$ & \\
\hline & Room $12 b$ & $?$ & $?$ & $?$ & $6.72 ?$ \\
\hline \multirow{3}{*}{$\begin{array}{l}\text { HU } 17 \\
\text { Area C }\end{array}$} & Room 17 & 4.00 & 3.40 & 13.60 & 13.60 \\
\hline & & & & & \\
\hline & Room 4 & 10.20 & 5.20 & 53.14 & \\
\hline \multirow{3}{*}{ HU 4} & Room 7 & 4.00 & 4.00 & 16.00 & \\
\hline & Room 8 & 5.00 & 3.80 & 19.00 & \\
\hline & Room 9 & 2.40 & 2.40 & 5.76 & 85.90 \\
\hline \multirow{6}{*}{ HU $5-22$} & Courtyard & 10.50 & 6.50 & 68.25 & \\
\hline & Room 5 & 7.80 & 4.50 & 35.10 & \\
\hline & Room 19 & 2.85 & 2.75 & 7.83 & \\
\hline & Room 20 & 4.25 & 2.75 & 11.68 & \\
\hline & Room 21 & 4.00 & 2.75 & 11.00 & \\
\hline & Room 22 & 2.90 & 2.75 & 7.83 & 141.69 \\
\hline HU 23-24 & Room & $23-245.00$ & 2.75 & 13.75 & 13.75 \\
\hline \multirow{3}{*}{ HU 25} & Courtyard? & 6.50 & 4.00 & 26.00 & \\
\hline & Room 25 & 5.00 & 3.50 & 17.50 & 43.50 \\
\hline & Courtyard? & 12.50 & 5.50 & 68.75 & \\
\hline \multirow[t]{2}{*}{ HU 28} & Room 28 & 10.50 & 4.50 & 47.25 & \\
\hline & Room 28a & 5.00 & 4.00 & 20.00 & 136.00 \\
\hline \multicolumn{6}{|l|}{ Area D } \\
\hline \multirow{4}{*}{ HU 6-16 } & Courtyard & 10.00 & 6.20 & 62.00 & \\
\hline & Room 6 & 6.20 & 5.50 & 34.10 & \\
\hline & Room 16 & 3.10 & 2.20 & 6.82 & 102.92 \\
\hline & Building 26 & 12.00 & 3.50 & 42.00 & 42.00 \\
\hline
\end{tabular}

Large multi-rooms HU are predominant in Area C and D. The courtyard portion of HU 4 that could be located along its north flank was not exposed. The unit, made of 4 rooms ranging in size from 5.76 to $53.14 \mathrm{~m}^{2}$ (table 1), measures 
$85.90 \mathrm{~m}^{2}$ in total surface extent. HU 5-22 excavated by the writer includes five rooms arranged around a large courtyard measuring $68.25 \mathrm{~m}^{2}$ (Figures 3 and 4). The main room 5 at the south end of the unit measures $35.10 \mathrm{~m}^{2}$. The 4 smaller rooms, $19,20,21$, and $22,7.83$ to $11.68 \mathrm{~m}^{2}$ in surface extent, were used for storage. Remarkably, HU 5-22 presented multiple flooring events and was equally used during the
Late Phase. Very few material culture elements were found on the unit floors, suggesting a planned abandonment.

There is a large open space along the northwest end of HU 5-22 but no sufficient information to connect it to any of the neighboring rooms (Figure 3). There are possibilities of courtyards, south and north of space XX.

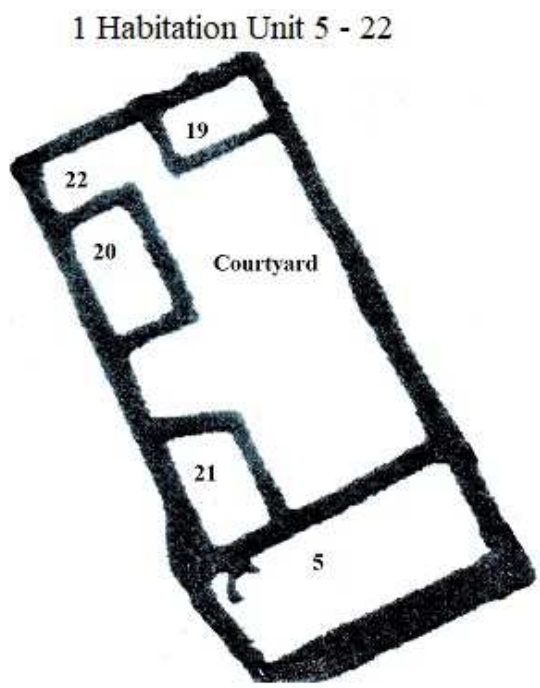

3- View of Room 6

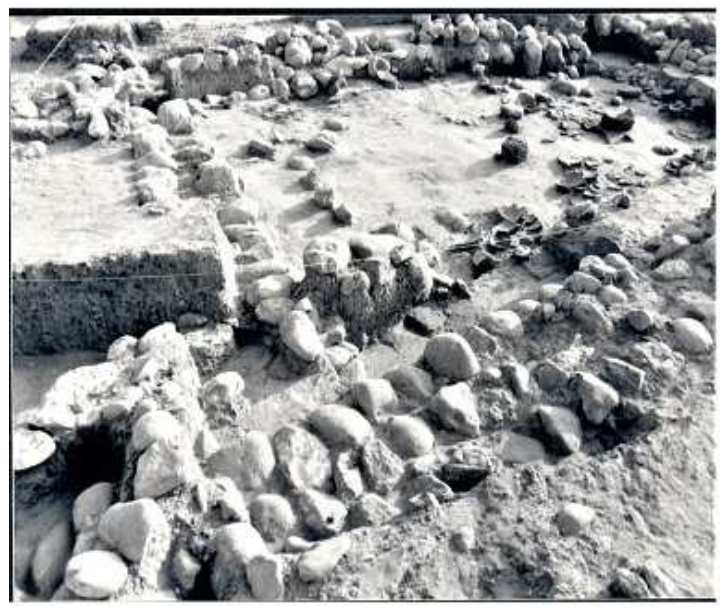

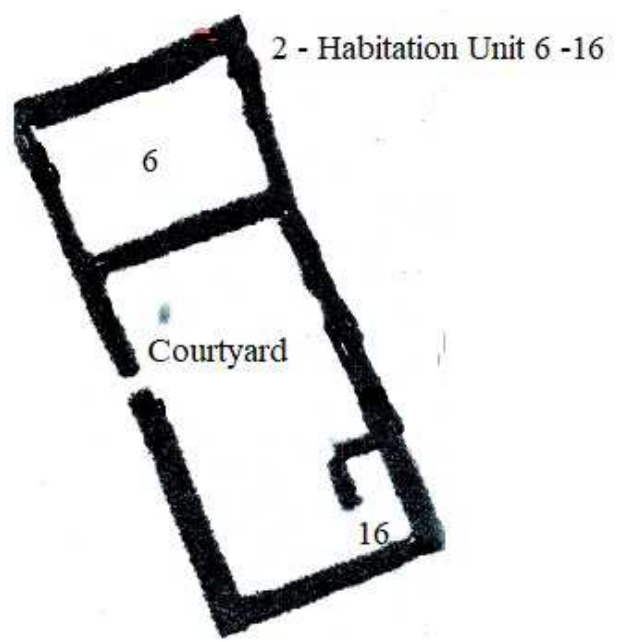

4 - Draft of Room 6

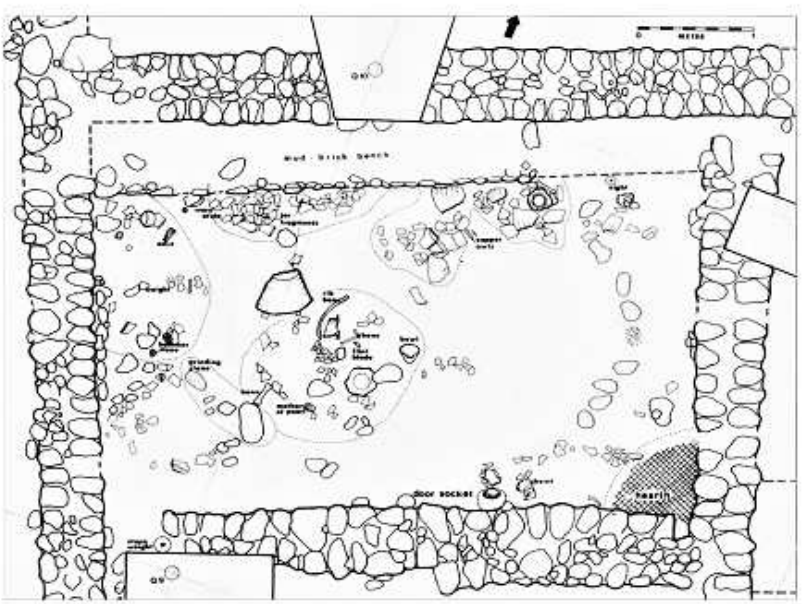

Figure 4. Shiqmim village habitation units.

HU 23-24 located in the north of the site (Figure 3) was not exposed entirely. It is not known if the space east of the room complex delimited in the southeast by a west-east wall was part of its courtyard. It measures $13.75 \mathrm{~m}^{2}$ partitioned into two rooms. HU 25 is oriented east-west. The room measuring $17.50 \mathrm{~m}^{2}$ is flanking a possible $26 \mathrm{~m}^{2}$ courtyard (Figure 4). HU 28, also oriented east-west, shares a wall with the previous unit. It is comprised of two rooms, 28 and 28a, respectively 47.25 and $20 \mathrm{~m}^{2}$ in surface extent, set along the north side of a $68.75 \mathrm{~m}^{2}$ courtyard.

Finally, HU 6-16 (Figure 4), excavated by the writer in 1984 and located in Area D, measures $102.92 \mathrm{~m}^{2}$. It is comprised of a relatively large $62 \mathrm{~m}^{2}$ courtyard, one large $34.10 \mathrm{~m}^{2}$ room for cooking and storage of domestic gear located at the NW end of the unit, and a small room 16 at the
SE corner of the unit. The recorded material culture pertaining to a broad range of activities was particularly rich and diverse: "1) storage is attested by four concentrations of ceramic basins and jars that collapsed along the mud-brick bench, possibly from storage racks set along the wall. 2) Food preparation activities are suggested by grinding stones in the southwest portion of the room and a hearth in the southeast corner. 3) Food consumption is indicated in the central portion of the room by food refuse, sheep/goat and cattle bones, a V-Shape bowl, a basin, and other vessels. And finally, a loose cluster of flint, stone and ceramic tools found along the margins of the northern and eastern walls. Evidence for "hide working" is attested by a copper awl inserted in a bone handle, associated with two spare copper points and several tabular scrapers. A special artifact, a 
hippopotamus ivory blade decorated with dots was also found on the room floor. Room 16, at the opposite end of the $\mathrm{HU}$, contains fresh flint flakes, cores and a number of cattle bones suggesting that butchering activities took place in that part of the courtyard [34].

Building 26, a $12 \mathrm{~m}$ long and $3.5 \mathrm{~m}$ wide construction located in the north of Area D was not used for habitation, The Main Phase site layout combines two houses orientations. The NW-SE orientation is predominant in the eastern part of the village, partly in Area A, and predominantly in Area C and D (Figure 3). W-E orientation is present in Area $\mathrm{B}$, part of Area $\mathrm{C}$ both south and north. At least 13 extended families' households may have been present at Shiqmim-village during its Main occupation Phase.

(ii). The Late Phase

Communities conflicts and rivalry suggested by evidence of house destructions and interpersonal violence may have affected Shiqmim-village population one way or the other and precipitated the end of the Main Phase. HU 23-24, HU
25, HU 28, part of HU 5-22 as well as the public building 28 located in the NW of the village were burnt down [37\}. A 1314 years old adolescent male, buried in a tightly flexed position in a circular pit was killed by mace head's blows on the skull [44].

The Late Phase settlement layout is radically different from the previous one. It consists of scattered well individualized habitation units organized into two distinct sets (Figure 5, table 2). Each of the recorded sets is made of 4 HU: HU 1-15, HU 2, HU 14, and HU 18 in the SW set and HU 5-22, HU 6-16, HU 13, and installation 27 in the NE one.

Single room units, measuring 30.80 to $54.64 \mathrm{~m}^{2}$ [HU 18 not included], are found exclusively in the SW set spread over Area A and B (Figure 8). HU 1-15 and HU 2, oriented NW-SE and measuring respectively 54.64 and $32 \mathrm{~m}^{2}$ are located at the center of the set. HU 14 in the NW and HU 18 in the SE, oriented SW-NE, are almost equidistant from the central HU, located respectively at 15 and $20 \mathrm{~m}$.

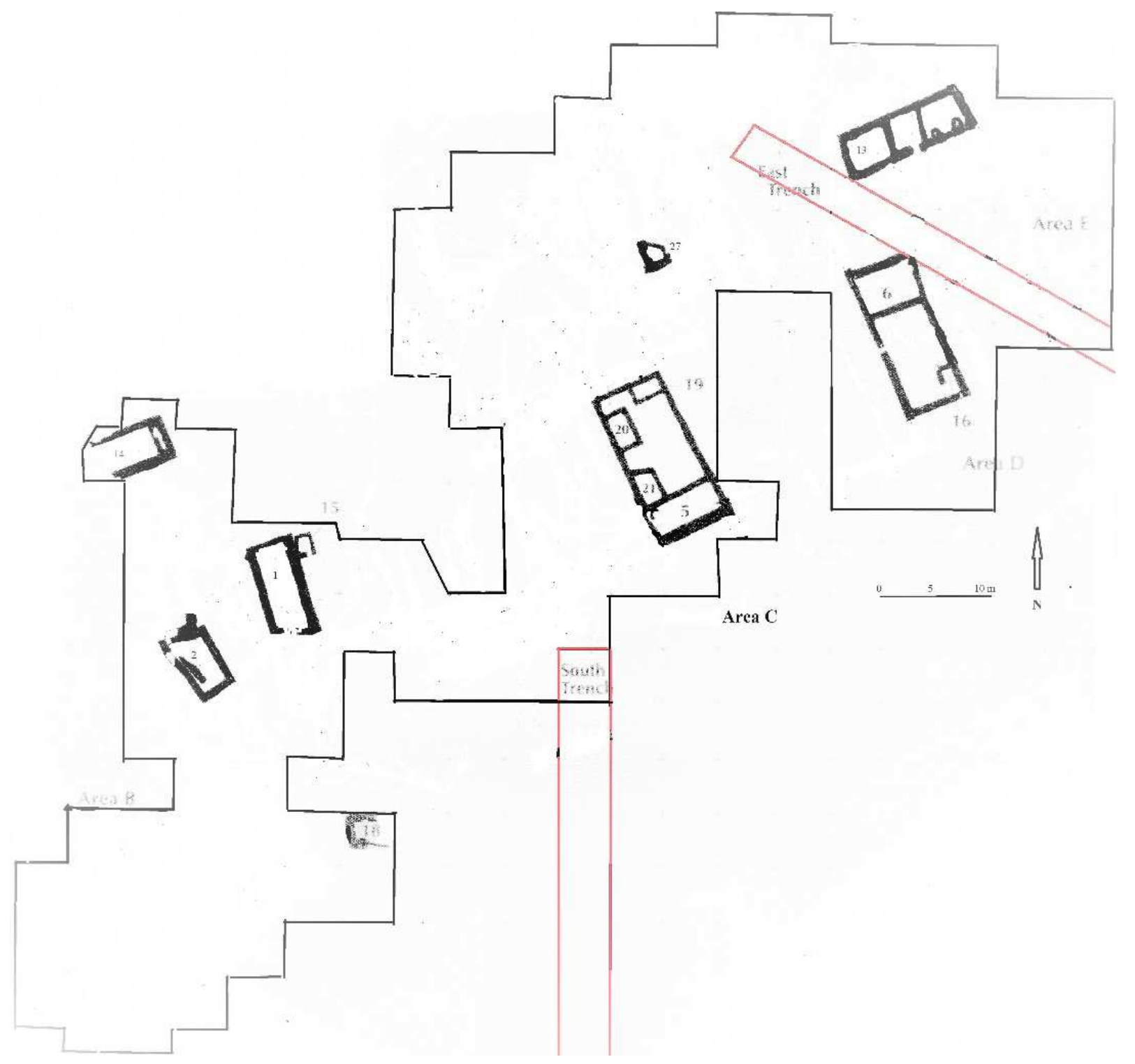

Figure 5. Shiqmim Late Phase. 
Table 2. Shiqmim Village Late Phase Housing.

\begin{tabular}{|c|c|c|c|c|c|}
\hline Habitation Unit & & Length (m) & Width (m) & Surface $\left(\mathrm{m}^{2}\right)$ & Aggregate $\left(\mathrm{m}^{2}\right)$ \\
\hline \multicolumn{6}{|l|}{ Southwest Set } \\
\hline \multirow{2}{*}{ HU 1} & Room 1 & 10.80 & 4.80 & 51.84 & \\
\hline & Room 15 & 2.00 & 1.40 & 2.80 & 54.64 \\
\hline HU 2 & & 8.00 & 4.00 & 32.00 & 32.00 \\
\hline HU 14 & & 7.00 & 4.40 & 30.80 & 30.80 \\
\hline HU 18 & & 3.60 & 3.20 & 11.52 & 11.52 \\
\hline \multicolumn{6}{|l|}{ Northeast Set } \\
\hline \multirow{5}{*}{ HU 5-22 } & Room 5 & 7.80 & 4.50 & 35.10 & \\
\hline & Room 19 & 2.85 & 2.75 & 7.83 & \\
\hline & Room 20 & 4.25 & 2.75 & 11.68 & \\
\hline & Room 21 & 4.00 & 2.75 & 11.00 & \\
\hline & Room 22 & 2.90 & 2.70 & 7.83 & 141.69 \\
\hline \multirow[b]{2}{*}{ HU 6-16 } & Courtyard & 10.00 & 6.20 & 62.00 & \\
\hline & Room 6 & 6.20 & 5.50 & 34.10 & \\
\hline \multirow{2}{*}{ HU 13} & 12.20 & 4.40 & 53.68 & 53.68 & \\
\hline & Installation 27 & $?$ & $?$ & $?$ & $? ?$ \\
\hline
\end{tabular}

Key: HU = Habitation Unit

The NE set, in Area C and D, is made essentially of multirooms $\mathrm{HU}$, measuring 53.68 to $141.69 \mathrm{~m}^{2}$, each with a unique design. HU-5-22 and HU 6-16 comprising a courtyard built during the Main Phase were still in use. HU 13 and installation 27 were newly added construction. The former, a $53.68 \mathrm{~m}^{2}$ house with three rooms, is oriented SW - NE. The later, a small triangular installation, may have been used for storage (table 2). The depopulation of the Shiqmim-village triggered a change in the site layout. The actual community structure may have been very different from that of the previous Main Phase.
In summary and excluding the very incomplete specimens, HU size ranges from 13.60 (HU 17) to $141.69 \mathrm{~m}^{2}$ (HU 5-22) in the Main Phase with frequent courtyards and 1 to 5 rooms (tables 3 and 4). The situation is comparable in the Late Phase with HU size ranging from 30.80 [HU 18 not included] to $141.69 \mathrm{~m}^{2}$ (HU 5-22). However, if the re-used HU 5-22 and HU 6-16 are not taken into consideration, the Late Phase built HU have no courtyard and ranged in size from 30.80 to $54.64 \mathrm{~m}^{2}$ (tables 3 and 4). The total build space, the portion of the village space with built facilities, dropped from 767.53 $\mathrm{m}^{2}$ in the Main Phase to $427.25 \mathrm{~m}^{2}$ in the Late Phase.

Table 3. Structure of Shiqmim-Village Habitation units.

\begin{tabular}{|c|c|c|c|c|}
\hline Habitation Units & $\operatorname{Size}\left(\mathrm{m}^{2}\right)$ & Courtyard $\left(\mathrm{m}^{2}\right)$ & Number of rooms & Built space \\
\hline \multicolumn{5}{|l|}{ Late Phase Housing } \\
\hline \multicolumn{5}{|c|}{ Southwest cluster } \\
\hline HU 1-15 & 54.64 & - & 2 & \\
\hline HU 2 & 32.00 & - & 1 & \\
\hline HU 14 & 30.80 & - & 1 & \\
\hline HU 18 & 11.52 & - & 1 & \\
\hline Total & & & & 128.96 \\
\hline \multicolumn{5}{|l|}{ Northeast cluster } \\
\hline HU 5-22 & 141.69 & 68.25 & 5 & \\
\hline HU 6-16 & 102.92 & 62.00 & 2 & \\
\hline HU 13 & 53.68 & - & 3 & \\
\hline Total & & & & 298.29 \\
\hline \multicolumn{5}{|c|}{ Main Phase Housing } \\
\hline \multicolumn{5}{|c|}{ Area A } \\
\hline HU 2 & 86.00 & 30.00 & 2 & \\
\hline HU 3 & 23.80 & - & 1 & \\
\hline HU XX & 24.50 & - & 1 & \\
\hline Total & & & & 134.30 \\
\hline \multicolumn{5}{|l|}{ Area B } \\
\hline HU 10 & 29.40 & - & 2 & \\
\hline HU 11 & $18.00 ?$ & - & 2 & \\
\hline HU 12 & $6.72 ?$ & - & 3 & \\
\hline HU 17 & 13.60 & - & 1 & \\
\hline Total & & & & 67.72 \\
\hline \multicolumn{5}{|l|}{ Area C } \\
\hline HU 4-9 & 85.90 & - & 4 & \\
\hline HU 5-22 & 141.69 & 68.25 & & 5 \\
\hline HU 23-24 & 13.75 & - & 2 & \\
\hline HU 28 & 135.75 & 68.75 & 2 & \\
\hline
\end{tabular}




\begin{tabular}{lllll}
\hline Habitation Units & Size $\left(\mathbf{m}^{2}\right)$ & Courtyard $\left(\mathbf{m}^{2}\right)$ & Number of rooms & Built space \\
\hline HU 25 & 43.50 & 26.00 & 1 & 420.59 \\
Total & & & & \\
Area D & & & \\
HU 6-16 & 102.92 & 62.00 & 2 & 144.92 \\
Building 26 & 42.00 & - & 1 & \\
Total & & & & \\
\hline
\end{tabular}

Table 4. Variability of habitation units size.

\begin{tabular}{llllll}
\hline Phase & $\mathbf{n}$ & Min $\left(\mathbf{m}^{2}\right)$ & Max $\left(\mathbf{m}^{2}\right)$ & Mean $\left(\mathbf{m}^{2}\right)$ & Range $\left(\mathbf{m}^{2}\right)$ \\
\hline Late Phase & 6 & 30.80 & 141.69 & 69.28 & 111.39 \\
Main Phase & 12 & 13.60 & 141.69 & 61.73 & 128.09 \\
\hline
\end{tabular}

Considering the significant drop in population from the Main to the Late Phase, one may wonder if part of Shiqmimvillage inhabitants left to create new settlements along the Nahal-Beersheva? Or if the documented trend was characteristic of the progressive devolution of the Northern Negev Chalcolithic societies? The Shiqmim Hamlets Project was launched to address that set of issues.

\subsection{The Shiqmim Hamlets Project}

The Shiqmim Hamlets Project tested three sites, Mezad Aluf, Shiqmim Mizrah, and Shiqmim Darom, located in the immediate periphery of Shiqmim-village, also known as Shiqmim countryside. The first is located approximately at $1.2 \mathrm{~km}$ west, the second at about $1 \mathrm{~km}$ east, and the third at few hundred meters south across the river bed (Figure 1).

\section{(i). Mezad Aluf}

Mezad Aluf is a 5.54 ha Chalcolithic village, located on the north bank and overlooking the Nahal Beersheva bed. It is a nucleated settlement extended over several loess hills with some circular burials excavated by Alon and Levy [43]. An area measuring $1000 \mathrm{~m}^{2}, 40 \times 25 \mathrm{~m}$ was inspected initially, presiding over the decision to excavate a $50 \mathrm{~m}^{2}$ portion containing the main excavation and two lateral trenches. The exposed archaeological deposit is $4 \mathrm{~m}$ thick. It is made of six sedimentary layers with evidence of four successive occupations (Figure 6):

1. 0-0.40 m: Loose brown yellow silty sand with building phase I remains

2. 0.40-1.30 m: Compact yellow silt above a thin white ashy layer, with at its top, the disturbed remains of Building phase II and a large storage pit

3. 1.30-2.80 m: Dark yellow compact silk containing the remains of Building Phase III

4. 1.30-2.60 m: Light yellow compact silt truncated by the storage pit and sedimentary unit 3 .

5. 2.60-4.00 m: Hard and compact silt containing the remains of Building Phase IV.

6. 3.80-4.00 m: Thin lenticular layer of light yellow sandy silt.

Mezad Aluf earliest occupation floor (BP IV) was exposed at $3.90 \mathrm{~m}$ below the surface. The exposed architectural remains consist of 2 walls stone foundations at right angle, each wall measuring $2 \mathrm{~m}$, delineating a square surface of approximately $4 \mathrm{~m}^{2}$ (Figure 6.). One wall is oriented NE-SW and the other NW-SE. A grindstone was found abutting the
SW-NE wall. If these remains were part of the corner of a house, it would have been oriented NW-SE as is the case for most of Shiqmim-village Main Phase habitation units.

Building Phase III remains were exposed at 2.7-2.8 m below the surface. They include a $0.5 \mathrm{~m}$ long and $0.5 \mathrm{~m}$ wide stone wall foundation, a floor, installations and scattered material culture items exposed on a $2.5 \times 2 \mathrm{~m}$ surface (Figure $6)$. The recorded installations include an altar abutting the wall, a cache in a pit containing $\mathrm{V}$-shape bowls, large fragments of a basalt vessel, a bone tool, another V-shape bowl on the floor and a cattle rib bone. Clearly, the uncovered assemblage is not an ordinary domestic kit, pointing to a special purpose use of that portion of Mezad Aluf site.

Building phase II remains were exposed at 0.40-0.60 m below the surface. They consist of extensively disturbed evidence of a rectangular house wall's foundation oriented West-East, a storage pit, and an undetermined square shape installation at its NE corner (Figure 6), The wall foundation, made of three parallel cobbles lines, is $3.5 \mathrm{~m}$ long and $0.75 \mathrm{~m}$ wide. The square-shape installation at the east end measures $1.5 \times 1.5 \mathrm{~m}$. It includes a circular shape stone feature, $0.50 \mathrm{~m}$ in diameter, containing a stone mortar. The storage pit abutting the house wall is bell-shape, measures $0.45 \mathrm{~m}$ in diameter at the opening, $1.5 \mathrm{~m}$ in diameter at bottom and is $1.00 \mathrm{~m}$ deep. Its fill is made of bedded layers of white and grey ash with and without charcoal pieces, silt, and sand.

Finally, Building Phase I material contained in the topsoil deposit with a house floor was exposed at $0.40 \mathrm{~m}$ below the surface. Both west and east end are missing (Figure 6). The uncovered house unit, oriented west-east, is $9 \mathrm{~m}$ long and 4 $\mathrm{m}$ wide. The west half of the north wall was made of mudbricks. The east half consisted of a single cobble line foundation. The unit's entrance located at the middle of the north wall is indicated by a stone door-socket. The south wall foundation, with an exposed short $3.5 \mathrm{~m}$ long and $0.5 \mathrm{~m}$ wide segment made of three parallel cobbles lines, was poorly preserved. A number of interesting features was recorded in the house. A horse-shoe shape hearth, oriented NE-SW with the opening in the SW, measuring $0.65 \mathrm{~m}$ in length and 0.45 in width, was found abutting the mudbrick wall in the west flank of the doorway. 2 complete vessels and 5 pits were recorded on the house floor. An elongated shallow pit 1 filled with ash was exposed all along the west wall segment. It contained some scattered wadi cobbles and a V-shape bowl. 
Pit 2 in the west half appears to have been a special installation. It measures 0.60 in diameter, is $0.50 \mathrm{~m}$ deep associated with post-holes in a triangular arrangement on its south half. It was filled with white clean ash without any fragment of material culture or charcoal. It may have been a dual purpose feature, used as heater and smoking apparatus.
Pit 5, a few meters south was a fire pit. The use of the remaining pit 3, 4, and 6 is unknown. An elaborate horseshoe shape stone installation found in the NE portion of the unit is interpreted as a "domestic altar" (Figure 6). It is square-shape, measures 0.80 by $0.75 \mathrm{~m}$, built with low stone walls set around a flat stone, open in the east.

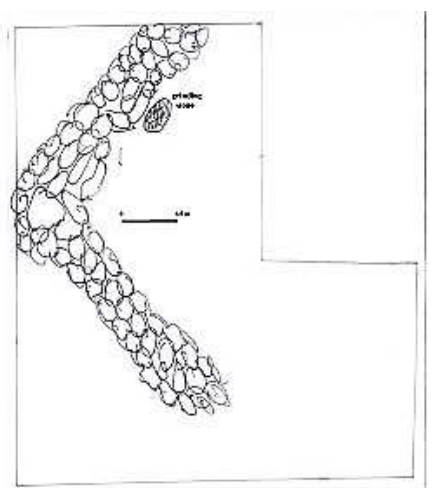

2 - Building phase IV

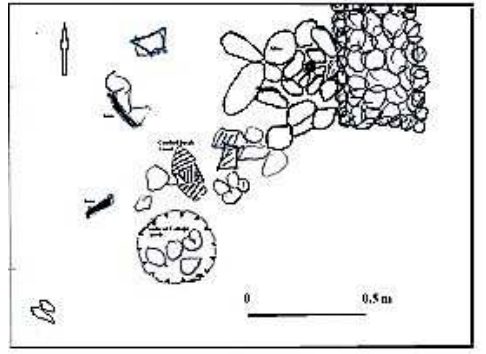

3 - Building phase III

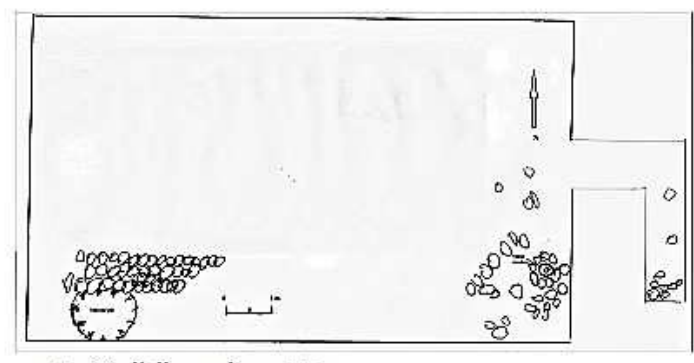

4 - Building phase II

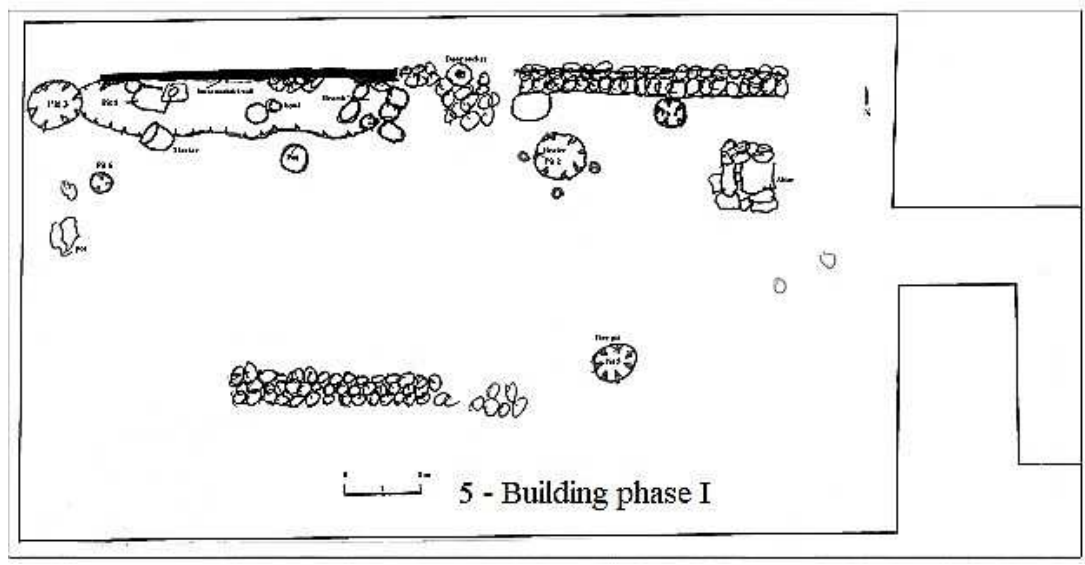

Figure 6. Mezad Aluf; Stratigraphic profile and Building phase IV to I.

Despite the significant impact of erosion that removed important portion of the unit walls foundation, it can be divided into two parts. The west half with the hearth, pots and mortar was used for storage and food preparation. The east half, with the altar, heater and fire-pit may have been part of the courtyard.

A charcoal sample collected from pit 3 in Building Phase I dates this occupation to $5090+/-70$ BP (Beta-160582), calibrated to 3800-3950 Cal BC (Online CalPal, Cologne Radiocarbon Calibration). This reading suggests that the earlier three occupations, from Building Phase IV to II, are much older and may span the entire Northern Negev Chalcolithic period. Based on the collected material, both architectural and artifactual, Mezad Aluf and Shiqmimvillage may have been settled initially at the same time and may have followed synchroneous parallel evolution.

(ii). Shiqmim-Mizrah

Shiqmim-Mizrah is a 1.20 ha hamlet on a loess hill located at approximately $1 \mathrm{~km}$ east of Shiqmim-village. A shallow surface inspection suggests the existence of subterranean rooms on the site's north slope. A hammer-shape excavation unit measuring $72 \mathrm{~m}^{2}$, made of a main $50 \mathrm{~m}^{2}(5 \times 10 \mathrm{~m})$ 
probe oriented WNW-ESE and an exploration $11 \times 2 \mathrm{~m}$ perpendicular trench oriented SSE-NNW, was set on the south flank of the site. Shiqmim-Mizrah hill, overlooks the Nahal Beersheva floodplain and presents a relatively steep slope. The drafted stratigraphic profile of the $12 \mathrm{~m}$ long trench connecting the site to the floodplain that has revealed a succession of 11 sedimentary layers is unfortunately not accessible. Refuse pits filled with ash and containing a certain amount of cultural remains were recorded along the edge of floodplain at $10 \mathrm{~m}$ south of the main excavation probe. Time limitations did not allow for a careful and complete excavation of the exploration trench. Despite this limitation and excluding the refuse pits found at the south end of the trench, the main excavation revealed the existence of at least 7 successive building phases.
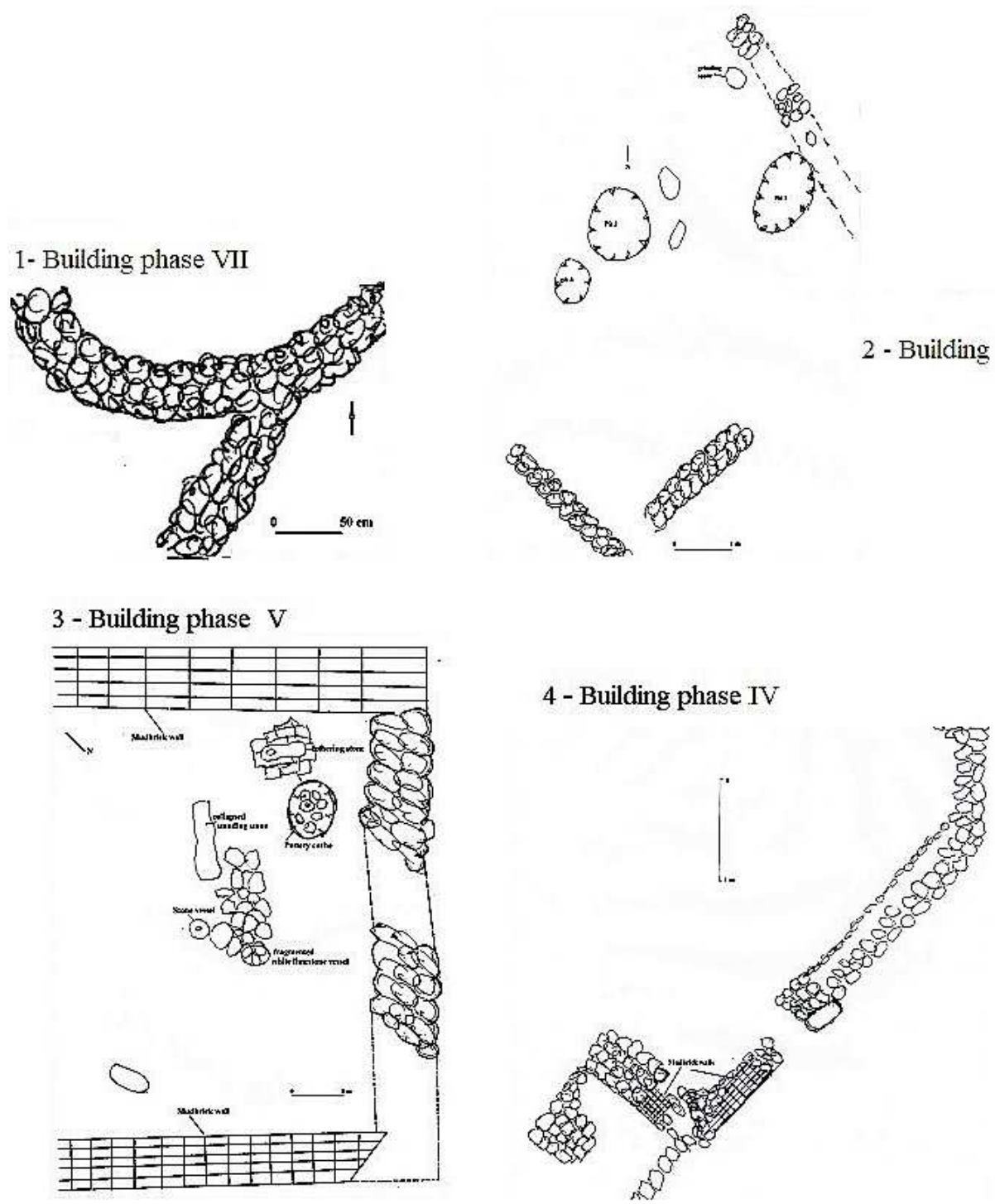

Figure 7. Shiqmim-Mizrah Building phase VII to IV.

The earliest building phase VII material was exposed at $2.70 \mathrm{~m}$ below the surface at the junction of the main excavation and the exploration trench. The probe is relatively small, measuring $2 \times 1.8 \mathrm{~m}$. The uncovered remains consist of two connected walls stone foundations. One is crescentshape with an exposed diameter of $2 \mathrm{~m}$ and the other is an attached straight $1.5 \mathrm{~m}$ long and $0.40 \mathrm{~m}$ wide wall (Figure 7).

Building phase VI remains were found at 2.30 to $2.50 \mathrm{~m}$ below the surface. They consist of partially preserved evidence of the SE end of a habitation unit. Portions of the foundations of the west, east, southeast walls are preserved differentially, delimiting a trapeze-shape space $6 \mathrm{~m}$ long and
$4 \mathrm{~m}$ wide (Figure 7). The exposed space containing 3 pits, a few scattered cobbles, and a grindstone, was probably the courtyard portion of a habitation unit. A charcoal sample collected from pit 2 dates this construction to $5870+/-170$ BP (Beta 160533), calibrated to 4560-4965 Cal BC (Online CalPal).

Building phase $\mathrm{V}$ is documented at $1.60-1.70 \mathrm{~m}$ below the surface and contains the remains of the SE end of a rectangular building with mudbricks west and east walls and a disturbed cobble foundation of the SE wall (Figure 7), impacted by later constructions. It is oriented NW-SE and measures $13.5 \mathrm{~m}^{2}, 4.5 \mathrm{~m} \mathrm{~N}-\mathrm{S}$ and $3 \mathrm{~m} \mathrm{E}-\mathrm{W}$. The recorded 
evidence suggests the building to have been built and used for cultic purposes. It includes a cache of V-shape bowls, a collapsed white standing stone, a tethering stone with a perforation set on a stone-made installation, a stone vessel, and a fragmented large white limestone vessel. The tethering stone is hypothesized to have been used to tie sacrificial animals.

Building phase IV architecture is recorded at $1.40-1.60 \mathrm{~m}$ below the surface, in direct continuity with the previous occupation. The cultic complex is expanded with the construction of an elaborate building (Figure 7). Some portions of the complex walls are built with mudbricks. The south wall is oriented east-west and measures $6 \mathrm{~m}$ in length, with a doorway marked by a large stone block. A $3 \times 3 \mathrm{~m}$ square redoubt was built at SW end of the complex. The delineated cultic space measures $33 \mathrm{~m}^{2}, 6 \mathrm{~m}$ long and $5.5 \mathrm{~m}$ wide.

Building phase III recorded at 1.00-1.20 m witnessed a new modification of the cultic construction. The building's doorway remained at the same place (Figure 8). An alley was opened along the east side, indicated by two parallel walls segments. Two architectural features connected by mudbricks were built at the west end of the south wall. One is crescentshape measuring $2 \mathrm{~m}$ in diameter. The other, probably the base of a square section large pillar, measures 1.5 by $1.5 \mathrm{~m}$.

Building phase II remains were exposed at $0.60-0.80 \mathrm{~m}$ below the surface. They are represented by two perpendicular wall foundations. One, oriented SW-NE is $3 \mathrm{~m}$ long and 0.40 $\mathrm{m}$ wide, and the other intersecting at right angle, $2 \mathrm{~m}$ long and equally $0.40 \mathrm{~m}$ wide (Figure 8 ).

Finally, Building phase I material exposed by erosion was visible at the site surface and helped in the selection of the location for the main excavation probe. It consists of a slightly incurved stone wall foundation, $2 \mathrm{~m}$ long, located at the southeast corner of the main excavation (Figure 8).
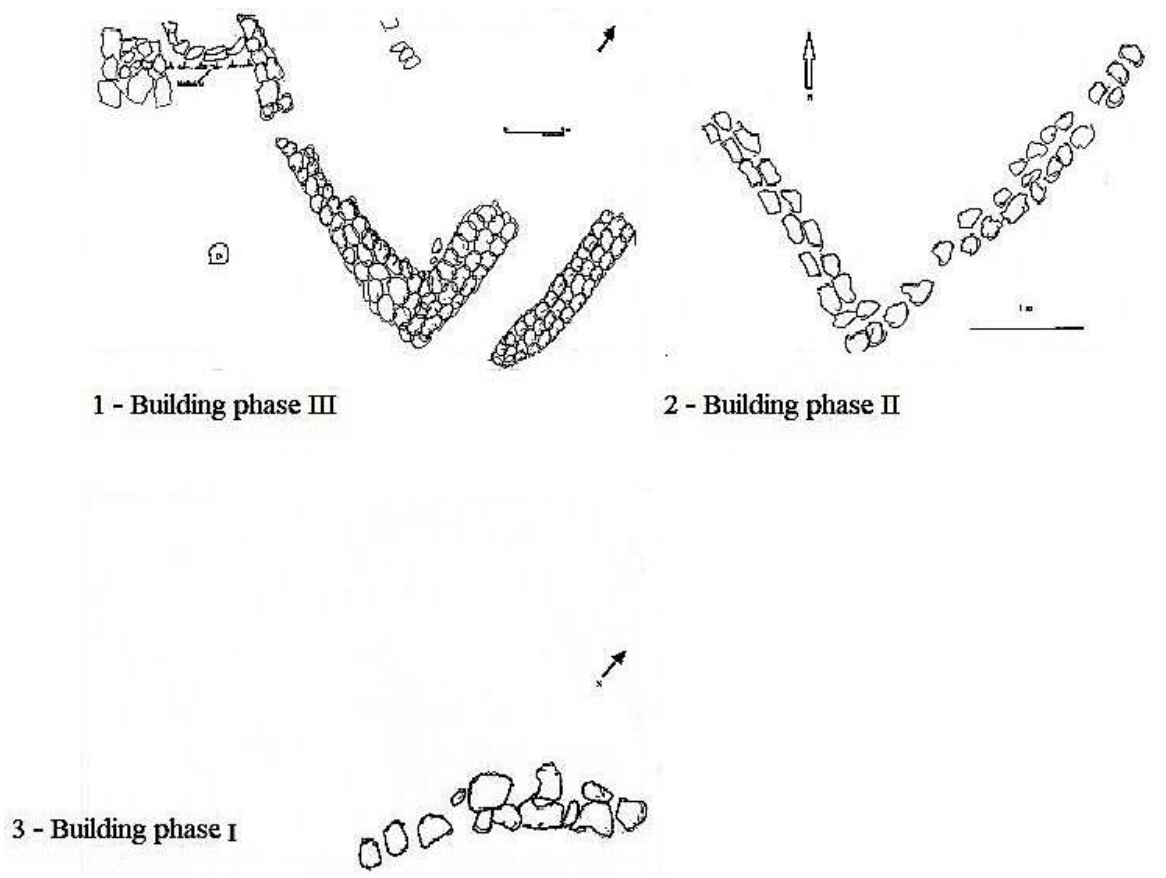

Figure 8. Shiqmim Mizrah Building phase III to I.

The sampled portion of Shiqmim-Mizrah hamlet witnessed interesting changes along the site's settlement history. The nature of the earliest BP VII occupation cannot be ascertained because of the small exposure of architectural features. BP VI, dated to 4965-4560 Cal BC (Beta-160582), features the southeast end of a habitation unit, very likely its courtyard portion. BP V to III witnessed the shift of the area to a cultic use. The initial cultic complex exposed in BP V was built in mudbricks predominantly. The monumentality of the cultic installation was initiated in BP IV and expanded in BP III. BP II witnessed the return to domestic use, with the south corner of a habitation unit-oriented NE-SW. The nature of BP I remains is difficult to determine because of the intensive erosion of the top deposit. For an important segment of its occupation history, Shiqmim-Mizrah hamlet may have been a special-purpose locality.

\section{(iii). Shiqmim-Darom}

Shiqmim-Darom is located on the south bank of the wadi at a few hundred meters $(400-500 \mathrm{~m})$ south of Shiqmimvillage. It is a 1.75 ha hamlet oriented west-east, parallel to the water course. An excavation unit $13.5 \mathrm{~m}$ long and $7.5 \mathrm{~m}$ wide, extended over $101.25 \mathrm{~m}^{2}$ and oriented ENE-WSW was set in the NW of the site. The top archaeological deposit was severely eroded exposing walls stone foundations. Two successive occupation were recorded in the top half meter of the deposit. A test trench was dug down to $1.6 \mathrm{~m}$ below the surface in the ESE of the probe to exclude the possibility of an underlying earlier occupation.

The earliest BP II occupation remains, significantly impacted by later constructions, were exposed at $0.40-0.50 \mathrm{~m}$ below the surface. The architectural evidence, made of different walls stone foundation segments, delimits an 
irregular rectilinear space oriented NE-SW measuring $12 \mathrm{~m}$ long and $4 \mathrm{~m}$ wide (Figure 9). The northeast round shape corner appears to have been re-modeled at least once. It includes a series of pits and walls segments that suggest this area to have been part of a courtyard. The south part of the

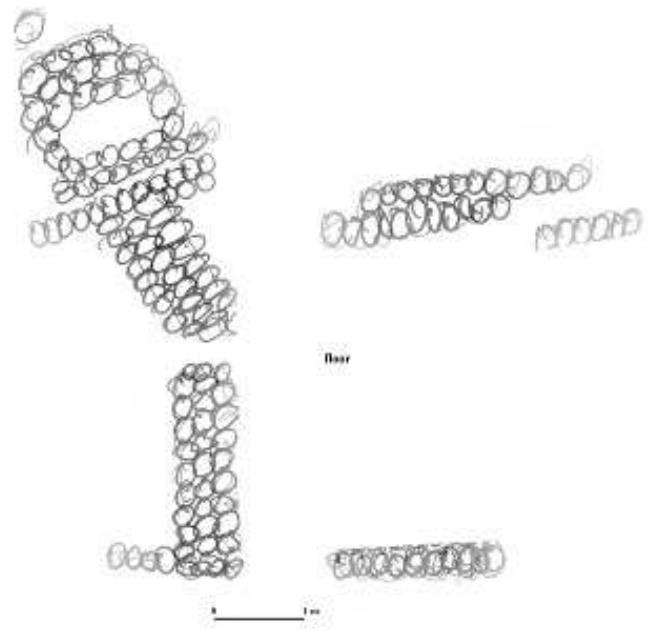

Building Phase I

house is complemented by a short E-W wall attached to an undetermined circular-shape installation. A charcoal sample collected from the small pit in the north corner dates this occupation to 4200-3975 CalBC (Beta-160531).
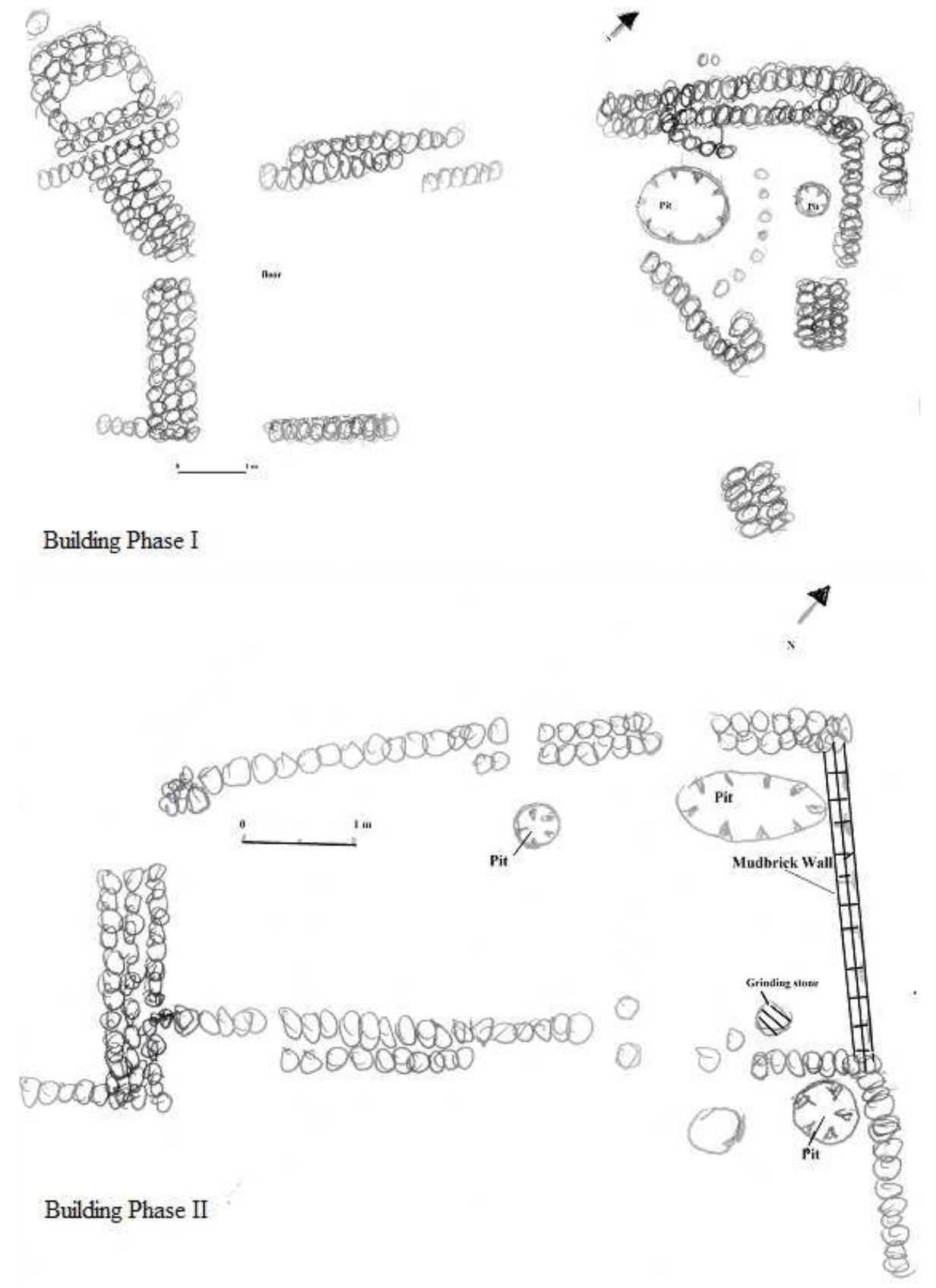

Figure 9. Shiqmim Darom Building phase II and I.

Building phase I remains are entirely inserted in the space delineated by the previous BP II building. The south and part of the east walls foundation were re-used in the construction of the new habitation unit. The trapeze-shape room, that appears to be attached to a courtyard located along its southeast flank (Figure 9), is $7 \mathrm{~m}$ long and 3-4 $\mathrm{m}$ wide, spread over $24.5 \mathrm{~m}^{2}$. The north wall was made of mudbricks without stone foundation. A complete vessel and a grindingstone were exposed in the NE corner of the room. If considered in relation to the partially exposed courtyard, BP I habitation unit was oriented NW-SE.

The habitation units recorded at Shiqmim-Darom present two distinct orientations that suggest the possibility of an occupation hiatus. The earlier BP II unit is oriented NE-SW and the later BP I one NW-SE. Shiqmim-Darom was very likely an extension of Shiqmim-village on the wadi south bank. 


\section{Result: The Dynamics of Shiqmim Site-Cluster}

It is unfortunate that all the charcoal samples collected from the sites sampled in the Shiqmim Hamlets Project were not submitted for radiocarbon dating [43]. Despite that limitation, the data available allow to open space for less dogmatic analyses of the dynamics of a Chalcolithic settlement cluster. A simpler and contextualized chronology of the Shiqmim settlement cluster was worked out without the radiocarbon readings from subterranean rooms (table 5).

The number of building phases recorded per site varies from 7 to 2. Shiqmim Mizrah presents a sequence of at least 7 building phases, without the evidence from the flood plain edge. BP VI, with the remains of a habitation unit oriented NW-SE, is dated to 4965-4560 Cal BC (Beta-160533). Shiqmim-village occupation sequence is made of 5 building phases (table 5). It started with the Early village accessed through deep probe and trenches dated to 5305-4363 Cal BC (RT- 649 D and RT-649B). It ended with the Late Phase BP I in stratum I, dated to 4321-3956 and 4440-3660 Cal BC (RT859C, D, E, RT-554A, RT-1341). Mezad Aluf displays a settlement history with 4 building phases in a $4 \mathrm{~m}$ thick cultural deposit. The earliest BP IV includes evidence of a construction oriented NW-SE. And the last one, in BP I, contains the remains of a habitation unit oriented W-E and dated to 3950-3800 CalBC (Beta-160532). Finally, ShiqmimDarom features two building phases. The earliest BP II with a disturbed habitation unit oriented NE-SW is dated to 42003975 Cal BC (Beta-160531). BP I habitation unit shifted back to the "standard" NW-SE orientation.

The chronological data processed up to this point are at variance with the frequently stated beginning and end of the Chalcolithic period, i.e. 4500 -3500 BC. Data converge and point to the end of the sixth- beginning fifth millennium BC for the initial development of the Shiqmim settlement cluster. Evidence from Shiqmim-village, Shiqmim-Darom and Mezad Aluf suggests the demise of the local chalcolithic occupation to have occurred at the end of the fifth-beginning fourth millennium BC, around 4321-3956 and 3950-3800 Cal BC (table 5). Axiomatically, variations in the timing of the beginning and end of the Chalcolithic occupation from one settlement cluster to the next are to be expected depending on actual local environments and implemented site location strategies.

Table 5. Contextualized Chronology of Shiqmim settlement cluster.

\begin{tabular}{|c|c|c|c|c|}
\hline Building Phase & Shiqmim-Mizrah & Shiqmim-village & Mezad Aluf & Shiqmim-Darom \\
\hline & & & Stratum 1: 3950-3800 & \\
\hline \multirow[t]{2}{*}{ BP I } & - & Stratum I: 4321-3956 & & \\
\hline & & Stratum IA: 4440-3660 & & Stratum 2: 4200-3975 \\
\hline BP II & - & $\begin{array}{l}\text { Stratum II: } 4327-4049 \\
\text { Stratum IIB: } 4492-3650\end{array}$ & - & \\
\hline BP III & - & Stratum III: $4548-4052$ & & \\
\hline BP IV & - & Stratum IV: 4766-4248 & - & \\
\hline BP V & & Early village: $5305-4363$ & & \\
\hline BP VI & HU pit: $4965-4560$ & & & \\
\hline BP VII & & & & \\
\hline
\end{tabular}

Combined stratigraphic analyses and radiocarbon dates can be relied upon to trace the most plausible settlement dynamics that presided over the formation of Shiqmim settlement cluster. Mezad Aluf, Shiqmim-village, and Shiqmim-Mizrah appear to have been settled at the same time by small mixed-farming communities, very likely at the end of the $6^{\text {th }}$-beginning of the $5^{\text {th }}$ millennium BC. The initial settlements, almost equidistant, located at 1 to $1.2 \mathrm{~km}$ from one to the next, were set along the north bank of Nahal Beersheva, Shiqmim-village grew faster, through internal population growth and immigration from other sites, and became a 9.5 ha central locality of the settlement cluster during its Main Phase. Mezad Aluf, also grew and became a medium-size 5.54 ha nucleated village. Shiqmim Mizrah developed into a small 1.20 ha hamlet that shifted to special ritual and cultic activities in BP V-III. Finally, ShiqmimDarom, featuring the occupation of the south bank, was very likely an off-shot of Shiqmim-village at the end of the fifth millennium BC. This extension may have occurred in two distinct episodes. First during Shiqmim-village Main phase for Shiqmim-Darom BP II and later during the Late Phase for Shiqmim-Darom BP I. The implemented site-location strategies, derived from an initial settlement system made of evenly spaced sites along a moving frontier, were partly centrifugal and centripetal.

\section{Conclusion}

Evolutionary time is an uninterrupted continuum. Names given to discrete space-time segments - Late Neolithic, Chalcolithic, Early Bronze Age, etc. - are convenient but not cast in bronze. There is a mosaic of Chalcolithic societies with overlapping material culture repertoires. The "Chalcolithization" process - adoption of the production and use of copper artifacts, polychrome pottery, and V-shape bowls - differentially affected diverse Late Neolithic mixed farming communities and took place at different times and places. The onset of wetter conditions opened the Northern Negev desert to human colonization at the end of the sixthbeginning fifth millennium BC. Some segments of the coastal plains Late Neolithic mixed-farming communities took advantage of the new situation to move southeastward. They adopted new cultural practices, expanded in new environments, and colonized fertile lands along the major 
river drainages of the hinterland.

Genomic data provide interesting complementary entries into the "chalcolithization process $[4,7,8,10]]$. The analyzed genetic data point to distinct populations cohorts for the Neolithic, Chalcolithic, and Bronze Age. "The Chalcolithic period.... witnessed major cultural transformations in virtually all areas of culture, .... craft production, mortuary and ritual practices, settlement patterns, and iconographic and symbolic expression. The current study provides insight into a long-standing debate in the prehistory of the Levant, implying that the emergence of the Chalcolithic material culture was associated with population movement and turnover. Our finding that the Levant ChL [Chalcolithic, emphasis mine] population can be wellmodeled as a three-way admixture between Levant_N [Neolithic] (57\%), Anatolia_N [Neolithic] (26\%), and Iran_ChL [Chalcolithic] (17\%), .... can only be explained by multiple episodes of population movement" [7].

As can be seen from the vantage point of the Shiqmim settlement cluster, the successful Chalcolithic adaptation to the semi-desertic northern Negev, that was marred with intercommunity conflicts and rivalry, lasted from 5305-4808 Cal BC (RT-649D) to 4042-3660 Cal BC (RT-859C), about 1200 years. Most of the northern Negev Chalcolithic polities were made of two-tiered settlement systems, i.e. a relatively large central village, medium-size villages, and hamlets. The devolution or collapse of these polities - also known as "chiefdoms" - took place at the beginning of the fourth millennium BC.

Four of the six sites from the Shiqmim site-cluster have already been tested. More work needs to be done to achieve a better understanding of the dynamics of Northern Negev Chalcolithic societies. Data obtained so far from the Shiqmim site-cluster point to the operation of both centripetal and centrifugal models. Relying on combined stratigraphic and radiocarbon dates evidence, the centrifugal model is documented by the synchronious foundation of Mezad Aluf, Shiqmim-village and Shiqmim-Mizra (Figure 2). They were equidistant small villages located along the Nahal Beersheva north bank. Settled initially at the very beginning of the period, they spanned the whole Chalcolithic period of the Northern Negev desert up to its collapse. Shiqmim-village, at midway between Mezad-Aluf and Shiqmim Mizra, attracted a larger population, expanded in size and became the sitecluster central locality at the peak of the region's Chalcolithic occupation. The centripetal model operated in the context of a sharp demographic downturn. It is illustrated by the nucleation of Shiqmin-village (Figure 4) and the foundation of Shiqmim-Darom, an attached hamlet on the south bank of Nahal Beersheva., across the river from Shiqmim.

Intra- and inter-community rivalry and competition paved the way to the demise and final collapse of Southern Levantine Chalcolithic polities. Genomics evidence point to significant disconnection between the Chalcolithic and the Early Bronze Age populations. "....finding of genetic discontinuity between the Chalcolithic and Early Bronze Age periods also resonates with aspects of the archeological record marked by dramatic changes in settlement patterns, large-scale abandonment of sites, many fewer items with symbolic meaning, and shifts in burial practices, including the disappearance of secondary burial in ossuaries. This supports the view that profound cultural upheaval, leading to the extinction of populations, was associated with the collapse of the Chalcolithic culture in this region" [8].

\section{Acknowledgements}

I am grateful to Professor Thomas E. Levy and late David Alon, co-directors of the "Chalcolithic Settlements of the Northern Negev, Israel", for their invitation to join in fieldwork in 1984. This led to 12 years of scientific crosscollaboration. I wish to thank all the bright international students who worked with me in the excavations at Shiqmimvillage and its hamlets.

\section{References}

[1] Blackham, M. 2002 Modelling Time and Transition in Prehistory: The Jordan Valley Chalcolithic. Oxford; BAR International Series.

[2] Bourke, S. J. 2001 The Chalcolithic period. In B. Macdonald, R. Adams, \& P. Bienkowski (Eds.), The archaeology of Jordan. pp. 107-163. Sheffield: Sheffield Academic Press.

[3] Epstein, C. 1998 The Chalcolithic culture of Golan, IAA Reports 4. Jerusalem: Israel Antiquities Authority.

[4] Eisenmann, S. et al 2018 Reconciling material cultures in archaeology with genetic data: The nomenclature of clusters emerging from archaeogenomic analysis. Scientific Reports 8: 13003.

[5] Gilead, I. 1988 The Chalcolithic period in the Levant. Journal of World Prehistory, 2, 397-443.

[6] Gilead, I. 1990 The Neolithic-Chalcolithic transition and the Qatifian of the Northern Negev and Sinai. Levant, 22, 47-63.

[7] Haber, M. et al 2017 Continuity and admixture in the last five millennia of Levanyine History from Ancient Canaanite and present-day Lebanese genome sequence. The American Journal of Human Genetics 101: 274-282.

[8] Harney, É. et al. 2018 Ancient DNA from Chalcolithic Israel reveals the role of population mixture in cultural transformation Nature Communications 9: 3336.

[9] Joffe, A. H., and Dessel, J. P. 1995 Redefining chronology and terminology for the Chalcolithic of the southern Levant. Current Anthropology, 36, 507-518.

[10] Lazaridis, L. et al 2016 Genomic Insights into the origin of farming in the Ancient Near East. Nature 536: 419-26.

[11] Lovell, J. and Y. M. Rowan, eds. 2011 Culture, Chronology and the Chalcolithic: Theory and Transition. Oxford; Oxbow Books.

[12] Rowan, Y. M. and J. Golden 2009 The Chalcolithic Period in Southern Levant: A Synthetic Review. Journal of World Prehistory 22: 1-92. 
[13] Braun, E. 2011 The transition from Chalcolithic to early Bronze $\mathrm{i}$ in the Southern levant: a 'lost horizon' Slowly revealed. In J. L. Lovell and Y. M. Rowan editors Culture, Chronology and the Chalcolithic: Theory and Transition. Pp. 160-177. Oxbow; London.

[14] Burton, M. M. and T. E. Levy 2011 the end of the Chalcolithic Period (4500-3600 BC) in the northern Negev desert, Israel. In J. L. Lovell and Y. M. Rowan editors Culture, Chronology and the Chalcolithic: Theory and Transition. Pp. 178-191. Oxbow; London.

[15] Bourke, S. J. 2001 The Chalcolithic period. In B. Macdonald, R. Adams, \& P. Bienkowski (Eds.), The archaeology of Jordan. pp. 107-163. Sheffield: Sheffield Academic Press.

[16] Bateson, G and M. C. Bateson 1987 Angel's Fears: toward an epistemology of the sacred. New York; Bantam Books.

[17] Eldredge, N. and S. J. Gould 1997 On punctuated equilibria. Science 276 (5311): 337-341.

[18] Burton, M. M. \& T. E. Levy 2012 Chalcolithic Social Organization Reconsidered: excavations at Abu Hof Village, northern Negev, Israel. Journal of the Israel Prehistoric Society 42: 137-192.

[19] Gilead, I. 1989 Grar: A Chalcolithic site in the Northern Negev, Israel. Journal of Field Archaeology, 16, 377-394.

[20] Levy, T. E. 1981 Chalcolithic settlement and subsistence in the northern Negev Desert, Israel. PhD Thesis. Ann Arbor; University Microfilms.

[21] Levy, T. E. and A. Holl, 1988a Les Premières chefferies de Palestine. La Recherche 203: 1166-1174; Levy.

[22] Levy T. E. and A. Holl 1988b Les Sociétés Chalcolithiques de la Palestine et l'émergence des Chefferies, Archives Européennes de Sociologie 29: 283-316.

[23] Fletcher, R. 2008 Some spatial analyses of Chalcolithic settlement in Southern Israel. Journal of Archaeological Sciences. 35: 2048-58.

[24] Winter-Livneh el al. 2010 Settlement patterns, Social complexity and agricultural strategies during the Chalcolithic Period in the Northern Negev, Israel. Journal of Archaeological Sciences 37: 284-294.

[25] Levy, T. E. 2005 Archaeology, Anthropology, and Cult: The Sanctuary at Gilat, Israel. London; Routledge.

[26] Holl, A. 1986 Economie et Societe Neolithique du Dhar Tichitt (Mauritanie). Paris; A.D.P.F

[27] Holl, A. F. C. 2002 The Land of Houlouf: Genesis of a Chadic Polity (BC 1900 - AD 1800). Ann Arbor; University of Michigan Museum of Anthropology.

[28] Holl, A. F. C. 2014 Archaeology of Mound-clusters in West Africa. Oxford; Archaeopress.

[29] Holl, A. F. C. and H. Bocoum 2013 Les Traditions
Mégalithiques de la Sénégambie. Paris, Editions Errance.

[30] Holl, A. F. C. and H. Bocoum 2017 Megaliths, Cultural Landscape and the Production of Ancestors. Saarbrucken; Editions Universitaires Europeennes.

[31] Blanton, R. E. 1978. Monte Albán: Settlement Patterns at the Ancient Zapotec Capital. New York: Academic Press.

[32] Holl, A. 1987 Mound formation processes and societal transformations: A case study from the perichadian plain. Journal of Anthropological Archaeology 6: 122-158; Schiffer, M. B. 1987 Formation Processes of the Archaeological Record. Albuquerque; University of New Mexico Press.

[33] Schiffer, M. B. 1987 Formation Processes of the Archaeological Record. Albuquerque; University of New Mexico Press.

[34] Levy, T. E. and A. Holl 1987 Theory and Practice in household archaeology: A case study from the Chalcolithic Village at Shiqmim. In T. E. Levy editor, Shiqmim I: studies concerning Chalcolithic Societies in the Northern Negev Desert, Israel (1982-1984). Pp. 373-410. International Series, Oxford; British Archeological Reports.

[35] Porath, Y. 1985 A Chalcolithic Building at Fasa'el. Atiqot 17: 1-19; Porath 1985: 5.

[36] Smith, R. 1984 Preface, In Land, Kinship and Life-cycle, edited by R. Smith, London: Cambridge University Press.

[37] Wilk, R. and W. I. Rathje 1982 Household Archaeology. American Behavioral Scientist 25: 617-639; Wilk and Rathje 1982: 620 .

[38] Levy, T. E. and A. Holl, 1988a Les Premières chefferies de Palestine. La Recherche 203: 1166-1174.

[39] Levy, T. E. and A. Holl 1988b Les Sociétés Chalcolithiques de la Palestine et l'émergence des Chefferies, Archives Européennes de Sociologie. 29: 283-316.

[40] Levy, T. E. et al 1991 Subterrannean Negev Settlement. National Geographic Research and Exploration 7: 394-413.

[41] Levy, T. E. et al 1993 Protohistoric Investigations at Shiqmim Chalcolithic Village and Cemetery: Interim Report on the 1988 Season. In W. G. Dever editor, Preliminary Excavation Reports. Association of American Schools of Oriental Research volume 51: 87-106.

[42] Levy, T. E., M. M. Burton and Y. M. Yorke 2006 Chalcolithic Hamlet excavations near Shiqmim, Negev Desert, Israel. Journal of Field Archaeology 31: 41-60.

[43] Alon, D and T. E. Levy 1985 Shiqmim: A Chalcolithic village and mortuary centre in the northern Negev. Paleorient 11 (1): $71-83$

[44] Dawson, L., T. E. Levy and P. Smith 2003 Evidence of interpersonal violence at the Chalcolithic Village of Shiqmim (Israel). International Journal of Osteoarchaeology 13: 115119. 